\title{
Benign concentric annular macular dystrophy
}

\author{
Distrofia macular anular concêntrica benigna
}

Luísa Salles de Moura Mendonça ${ }^{1}$, Luciana Castro Lavigneㄹ, Luis Fernando Oliveira Borges Chaves ${ }^{1}$, José Maurício Botto de Barros Garcia', David Leonardo Cruvinel Isaac ${ }^{1}$, Marcos Ávila ${ }^{1}$

\begin{abstract}
The purpose of the authors is to show clinical findings of a patient with benign concentric annular macular dystrophy, which is an unusual condition, and part of the "bull's eye" maculopathy differential diagnosis. An ophthalmologic examination with color perception, fluorescein angiography, and ocular electrophysiology was performed.

Keywords: Retinal diseases/diagnosis; Fluorescein angiography; Electrophysiology; Macula lutea/pathology; Diagnosis, differential; Case reports
\end{abstract}

\section{RESUMO}

O objetivo dos autores é detalhar o quadro clínico de um paciente com distrofia macular anular concêntrica benigna, quadro raro, que compõe o diagnóstico diferencial das maculopatias em alvo. Realizou-se avaliação oftalmológica com auxílio de testes de percepção de cores, angiofluoresceinografia e eletrofisiologia ocular.

Descritores: Doenças retinianas/diagnóstico; Angiofluoresceinografia; Eletrofisiologia; Mácula lútea/patologia; Diagnóstico diferencial; Relatos de casos

\footnotetext{
${ }^{1}$ Universidade Federal de Goiás, Goiânia (GO), Brazil.
}

The authors no conflicts of interest

Received for publication 14/10/2014 - Accepted for publication 13/01/2015 


\section{INTRODUCTION}

B enign concentric annular macular dystrophy (BCAMD) (OMIM 153870; Online Mendelian Inheritance in Man, http://www.ncbi.nlm.nih.gov/omim) is an uncommon disorder, initially characterized by paracentral ring scotoma with a central hyperpigmentation of the retinal pigment epithelium (RPE) and relatively good visual acuity ${ }^{(1-3)}$. The first report of BCAMD was published in 1974, in a family with an autosomal dominant trait ${ }^{(4)}$.

A ringlike hyperfluorescence is typically found in fluorescein angiographic images. It is a result of a window defect in the atrophic macular pigment which provides the characteristic "bull's eye" maculopathy ${ }^{(1,4)}$. Electroretinogram (ERG) is usually normal or slightly abnormal ${ }^{(1,2)}$. Studying the patients' color perception, some of them show predominant defects in the blue yellow axis, though this finding is not constant ${ }^{(1,5,6)}$.

The differential diagnosis of a "bull's eye" maculopathy includes chloroquine and hydroxychloroquine toxicity, Stargardt's disease, central areolar choroidal atrophy, chronic macular hole and cone dystrophy. Patients with BCAMD do not have a prior history of regular chloroquine intake or symptoms related to photoreceptors dystrophy, such as photophobia and severely defective color vision ${ }^{(1)}$.

The present study reports a case of a patient with typical clinical findings of BCAMD.

\section{Case Report}

A 41-year-old male, native of Rio de Janeiro, Brazil, presented at CEROF-UFG complaining about nyctalopia and gradual deterioration of visual acuity, in the last 4 years. His past medical history and family medical history were unremarkable. He did not refer photophobia or history use of regular oral medications. He was initially treated in another clinic in Rio de Janeiro, where the disorder was diagnosed as cone rod dystrophy.

His initial examination showed a best corrected visual acuity of 20/50 in the OD and 20/30 in the OS. Anterior segment biomicroscopy was normal in OU. Intraocular pressure was 15 $\mathrm{mmHg}$ in the OD and $13 \mathrm{mmHg}$ in the OS. Fundoscopy evaluation had shown bilateral area of perifoveal hypopigmentation with an annular conformation and a concentric aspect in the macular region, but sparing the center of the fovea (figure 1). Fundus periphery was normal. Fluorescein angiography had shown typical "bull's eye" maculopathy pattern (figure 2). The Farnsworth-Munsell D15 color test was performed, which presented no visual dysfunction.

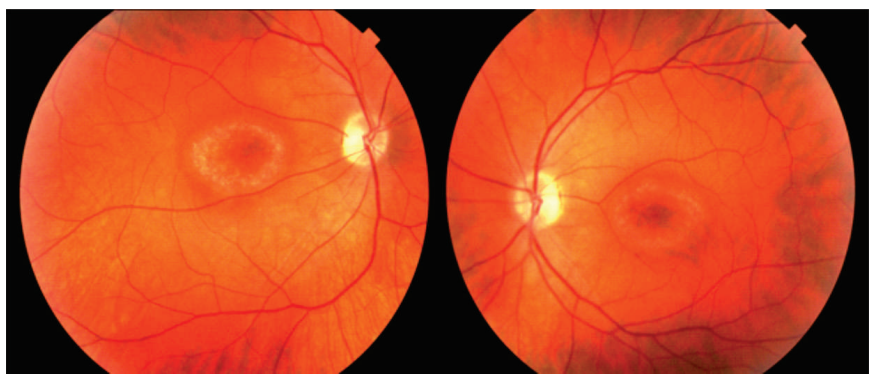

Figure 1. Fundus photographs showing an annular and concentric area of hipopigmentation in the macular region, with a central, irregular and hyperpigmented area

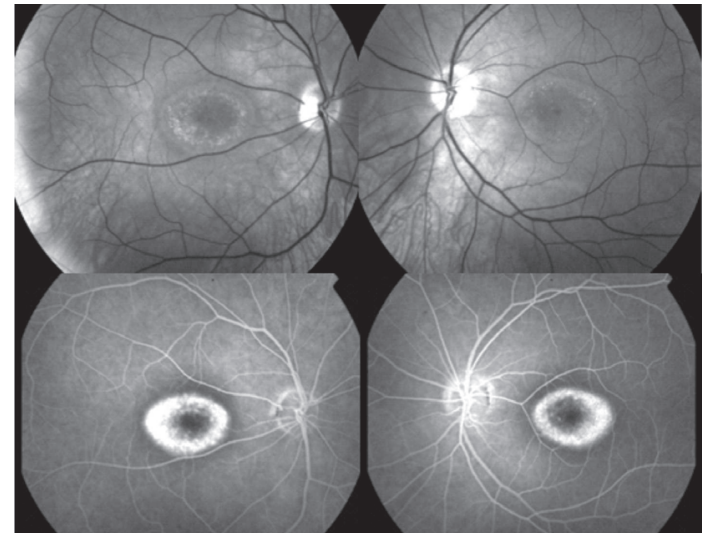

Figure 2. Fundus imaging (top row) and angiography with fluorescein (bottom row), demonstrating a typical bull's eye maculopathy image

The standard ERG was normal (figure 3). The parameters were abnormal on the pattern Visual evoked potential (VEP), presenting decreased amplitude and prolongation of the latency (figure 4).

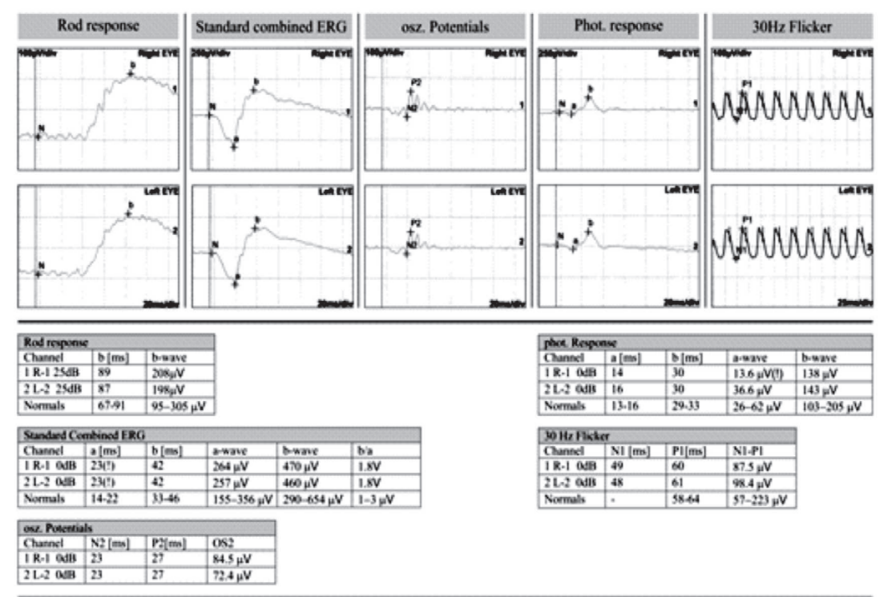

Figure 3. Standard ERG and $30 \mathrm{~Hz}$ Flicker with normal findings

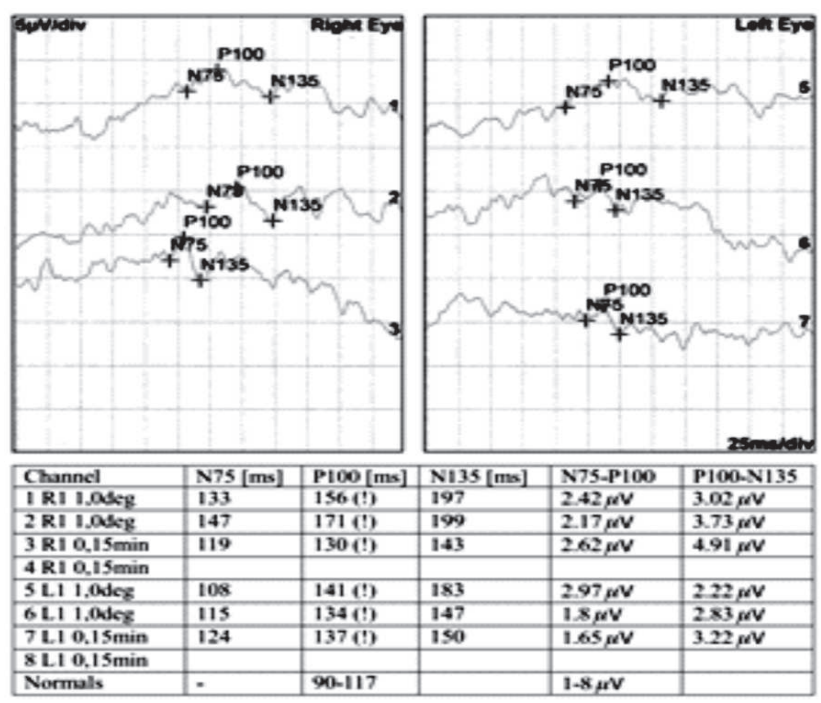

Figure 4. Pattern VEP with decreased amplitude and prolongation of the latency 
After evaluating all this clinical features, the patient was diagnosed with BCAMD. In 3 years of follow up, he did not show any changes in visual acuity, maintaining the same fundoscopy and angiographic findings and ERG without abnormalities. After that, he did not return to an appropriate follow-up in our service.

\section{Discussion}

BCAMD is a highly unusual disorder ${ }^{(3)}$. A search on the terms "annular" "macular" and "dystrophy" on PubMed website found 11 original related articles. After the initial report by Deutman in 1974, the term "benign" was applied to a general condition of a good visual acuity as part of one of the main clinical features of the BCAMD ${ }^{(1,3)}$.

Recently, a mutation in the IMPG1 was related to BCAMD, but this relation is not confirmed ${ }^{(1,2)}$. The IMPG1, residing at the BCAMD locus, in the chromosome 6 might result in a Leu579Pro amino acid substitution, playing a major role in its pathogenesis ${ }^{(2)}$.

Fundus retinography typically shows a "bull's eye" configuration with a RPE's annular ring atrophy, corresponding to the fluorescein angiography of a circular hyperfluorescence ${ }^{(1,3)}$.

While patients frequently show a "benign" course with good visual acuity for a long time, others may present a pronounced involvement of the peripheral retina associated with a severe photoreceptor dysfunction $^{(1,3)}$. A long term follow-up study of an affected Dutch family showed that there was a pronounced involvement of the peripheral retina, increased photoreceptor dysfunction, waxy optic disc, arteriolar attenuation and further decline of the ERG, as found in retinitis pigmentosa ${ }^{(2,3)}$.

Regarding color vision defects in BCAMD, the existence of defects in the blue yellow axis is predominant, though not constant. Some studies showed mild defects only, without any predominant axis of confusion ${ }^{(1,5,6)}$.

The ERG is typically normal or slightly abnormal ${ }^{(1,3)}$. The normal findings obtained on ERG suggest that this is a focal dysfunction rather than a generalized fundus disorder, but some testing revealed a photoreceptor dysfunction with a slight predominance of rod dysfunction above cone dysfunction ${ }^{(1,2,7)}$. A study showed a "bulls' eye" maculopathy, associated with a negative ERG in four unrelated patients who had normal vision initially, but with progressive loss of visual acuity, preserved cone response in ERG, and mild to moderate color deficiency. It was thought that they had a similar condition with BCAMD, but no signs at all of an autosomal dominantly disease ${ }^{(8)}$. The VEP findings, to our knowledge, have not been described previously in patients with BCAMD.

The optic coherence tomography (OCT) findings in this condition may suggest new pathological abnormalities. A limitation of our case report is the absence of the OCT images, because the patient was examined prior to OCT introduction in clinical practice, and, after that, he did not return to an appropriate follow-up. However, OCT alterations are mild and, to our knowledge, have been described only in one case report in 2005 , in which they did not contribute to establish the diagnosis $^{(3)}$. The abnormalities include high and low reflectivity areas under the RPE, similar to the OCT findings seen in adult vitelliform macular dystrophy. The relatively normal neurosensory retina at the fovea probably explains the good visual acuity and mild ERG abnormalities ${ }^{(3)}$.
The angiographic aspect, family history and hereditary pattern are the most relevant data when determining a differential diagnosis among variable clinical conditions ${ }^{(1)}$. Retinopathy secondary to anti malarial drugs requires a history of sustained intake of chloroquine or hydroxychloroquine. It is difficult to differentiate BCAMD and photoreceptors dystrophies. Symptoms and clinical signs, such as photophobia, progressive central vision loss, important defect in color vision and an extremely altered photopic electroretinogram are found in cone rod dystrophy ${ }^{(1,2)}$. Stargardt's disease has an autosomal recessive inheritance and shows a marked reduction in central visual acuity, although, in the initial stages, the fundus imaging may appear normal. The characteristic "silent" choroidal angiographic and the altered electrooculogram are also important to its diagnosis ${ }^{(1)}$.

In the reported case, regarding the good visual acuity, after studying the fluorescein angiography with corresponding retinographies, and the results of the standard ERG and VEP, BCAMD was diagnosed. The differential diagnosis include all conditions with the "bull's eye" maculopathy configuration ${ }^{(1,6)}$.

\section{References}

1. Gomez-Faiña P, Alarcón-Valero I, Buil Calvo JA, Calsina-Prat M, Martín-Moral D, Lillo-Sopena J, et al. Distrofia macular anular benigna concéntrica. Arch Soc Esp Oftalmol. 2007; 82(6):373-76.

2. van Lith-Verhoeven JJ, Hoyng CB, van den Helm B, Deutman AF, Brink HM, Kemperman MH, et al. The benign concentric annular macular dystrophy locus maps to 6p12.3-q16. Invest Ophthalmol Vis Sci. 2004; 45(1):30-5.

3. Burton BJ, Holder GE, Duguid G, Gregory-Evans K. Optical coherence tomography findings in benign concentric annular dystrophy. Eye. 2005; 19(6):699-701.

4. Deutman AF. Benign concentric annular macular dystrophy. Am J Ophthalmol. 1974; 78(3):384-96.

5. van den Biesen PR, Deutman AF, Pinckers AJ. Evolution of benign concentric annular macular dystrophy. Am J Ophthalmol. 1985; 100(1):73-8.

6. Sadowski B1, Rohrbach JM, Partsch M, Schiefer U. Benign concentric annular macular dystrophy. Klin Monbl Augenheilkd. 1994; 205(3):173-5.

7. Coppeto J, Ayazi S. Annular macular dystrophy. Am J Ophthalmol. 1982; 93(3):279-84.

8. Miyake Y, Shiroyama N, Horiguchi M, Saito A, Yagasaki K. Bull's eye maculopathy and negative electroretinogram. Retina. 1989;9(3):210-5.

\section{Corresponding author:}

Luísa Salles de Moura Mendonça

Rua 9, n 663, apto 602 - Setor Oeste

Zip code 74120-010 - Goiânia (GO), Brazil

E-mail: luisasmmendonca@gmail.com 